\title{
Biomechanical comparison of graft structures in anterior cruciate ligament reconstruction
}

\author{
Breck R. Lord ${ }^{1,2} \cdot$ Hadi El-Daou $^{1}$ - Bhushan M. Sabnis ${ }^{2} \cdot$ Chinmay M. Gupte $^{3}$ • \\ Adrian M. Wilson ${ }^{2} \cdot$ Andrew A. Amis ${ }^{1,3}$
}

Received: 16 May 2016 / Accepted: 1 September 2016 / Published online: 16 September 2016

(c) The Author(s) 2016. This article is published with open access at Springerlink.com

\begin{abstract}
Purpose Double-bundle (DB) anterior cruciate ligament (ACL) reconstruction may offer kinematic restoration superior to anatomic single bundle (SB), but it remains technically challenging. The femoral attachment site has the most effect on ACL graft isometry, so a simplified three-socket (3S) construct which still uses two sockets to cover the femoral ACL attachment is attractive. It was hypothesised that ACL reconstruction using three- and four-socket techniques would more closely restore native knee kinematics compared to anatomic two-socket (SB) surgery.

Methods Nine cadaveric knees were used to evaluate the kinematics of ACL-intact, ACL-deficient, anatomic SB, three-socket, and DB arthroscopic ACL reconstructions. Suspensory fixation was used, and grafts were tensioned to match the anterior draw of the intact knee at $20^{\circ}$. A sixdegree-of-freedom robotic system measured knee laxity under $90 \mathrm{~N}$ anterior tibial force and rotational laxity under $5 \mathrm{~N}-\mathrm{m}$ torque. Combined moments were applied to simulate the pivot-shift subluxation: $4 \mathrm{~N}$-m internal rotation and $8 \mathrm{~N}-\mathrm{m}$ valgus.

Results Significant differences between reconstructions were not found during anterior tibial loading, apart from SB being more lax than $\mathrm{DB}$ at $60^{\circ}$ flexion. All reconstructions

Andrew A. Amis

a.amis@imperial.ac.uk

1 The Biomechanics Group, Department of Mechanical Engineering, Imperial College London, London SW7 2AZ, UK

2 Basingstoke and North Hampshire Hospital, Basingstoke, UK

3 Musculoskeletal Surgery Group, Department of Surgery and Cancer, Imperial College London School of Medicine, Charing Cross Hospital, London, UK
\end{abstract}

produced comparable laxity to the intact state, apart from $\mathrm{SB}$ at $60^{\circ}$. Significant differences between reconstructions were not found at any flexion angle during tibial internal/ external applied torques. Under combined loading, DB produced significantly less laxity than SB constructs apart from anterior tibial translation at $0^{\circ}$ and internal rotation at $45^{\circ}$. $3 \mathrm{~S}$ and $\mathrm{DB}$ were comparable to the native knee throughout.

Conclusion Although $3 \mathrm{~S}$ restored laxities to a similar extent to DB, significant superiority over SB surgery was not observed. Although statistically significant differences were found between SB and DB surgery during anterior tibial and simulated pivot-shift loading, both remained similar to the native knee. The clinical relevance is that this study did not support an ACL graft construct more complex than an anatomic single bundle.

Keywords Anterior cruciate ligament - Anatomic ACL reconstruction · TriLink - Single bundle $\cdot$ Double bundle . Knee kinematics $\cdot$ Pivot shift $\cdot$ Robotics

\section{Introduction}

The anatomy of the ACL is complex, with a multitude of small fascicular bundles twisting around each other during knee flexion [15], commonly simplified into two functional bundles: anteromedial (AM) and posterolateral (PL) based on their tibial attachment sites [13]. These contribute to knee stability in a specific pattern, depending on the knee flexion angle [1, 11, 39]. This pattern reflects the structure of the native ACL, functioning as groups of fibres which lengthen and slacken across the range of motion [16, 39].

The optimal method of ACL reconstruction is yet to be determined. Biomechanical [4, 25, 33, 34] and clinical [19, 
$21,26,42,52]$ papers have demonstrated superior restoration of native knee kinematics or improved function after double-bundle (DB) surgery than single-bundle (SB) surgery; however, equivocal results have also been reported $[14,23,24,30,32,47,48]$. Double-bundle surgery is more complex, imposing greater technical demand, longer operative time, the possibility of tunnel convergence and notch impingement, and greater expense $[3,7,8]$. A DB reconstruction is defined in this paper as having two grafts, each with separate bone sockets at each end, forming a foursocket construct.

The femoral attachment site has the most effect on ACL graft isometry and tension with knee flexion [16, 27, 41], so a simplified graft construct which covers most of the femoral ACL attachment is attractive. Therefore, the purpose of this study was to examine the relative merits of a three-socket (3S) construct, with a V-configuration graft located into a single tibial tunnel and double femoral ACL graft tunnels [49]. Unlike previous work, the present study evaluated ACL reconstructions using cortical suspensory fixation, enabling different tensioning angles for each graft bundle. It was hypothesised that ACL reconstruction using three- and four-socket techniques would more closely restore native knee kinematics compared to anatomic single-bundle two-socket ( $\mathrm{SB}$ ) surgery, whilst $3 \mathrm{~S}$ surgery would restore native knee kinematics to a similar extent as four-socket DB surgery. Although there have been many previous studies of ACL graft constructs, there has not been a study which has compared the relative biomechanical ability of each of the three constructs to restore native knee laxity.

\section{Materials and methods}

\section{Specimen preparation}

Nine fresh-frozen knees from donors with a mean age of 66 years (SD, \pm 7.6 years; range, $54-78$ years; five female and four male; three left and six right), were used. They were screened for prior ACL injury, surgery, and soft tissue or bony disease. The semitendinosus and gracilis tendons were harvested in a retrograde manner via a $30-\mathrm{mm}$ oblique incision over the pes anserinus. The femur was cut $190 \mathrm{~mm}$ from the joint line and the soft tissues resected from the proximal $80 \mathrm{~mm}$. The tibia was cut $140 \mathrm{~mm}$ from the joint line and the soft tissue resected from the distal $60 \mathrm{~mm}$. The fibula was transfixed to the tibia with a tri-cortical screw.

\section{Robotic system}

Each knee was secured within a robotic biomechanical testing system, comprising of a six-degree-of-freedom (DOF)

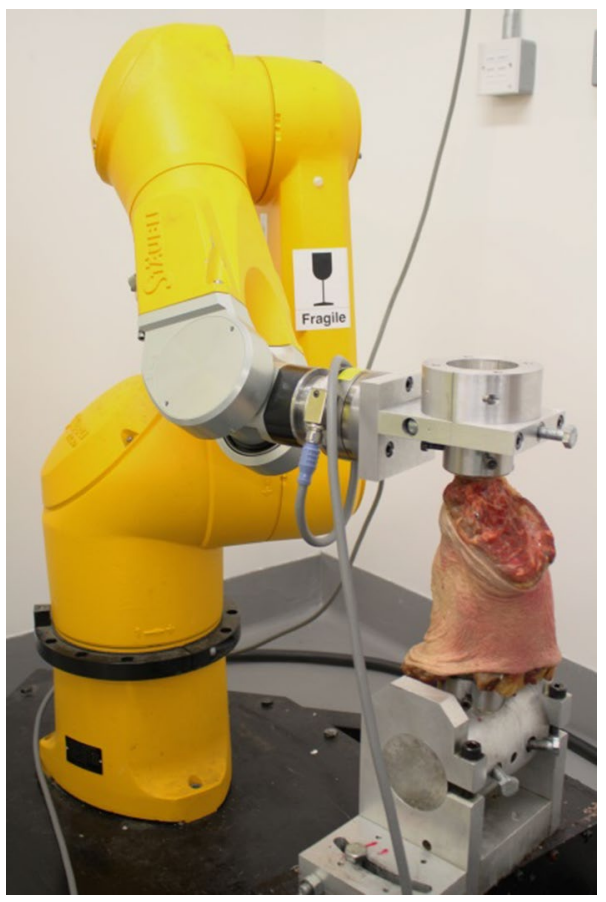

Fig. 1 Robotic joint manipulator. The tibia was mounted within a custom fixture attached to a universal force-torque sensor (Omega 85, ATI Industrial Automation) affixed to the end effector of a robot (TX90, Stäubli Ltd, Switzerland), while the femur was mounted to the fixed base

robotic manipulator (TX90, Stäubli Ltd, Switzerland), a six-axis universal force sensor (Omega 85, ATI Industrial Automation), with custom-designed tibial and femoral fixtures (Fig. 1). The force sensor had a resolution of 0.3 , 0.3 and $0.4 \mathrm{~N}$ for $X, Y$ and $Z$ axis forces, respectively, and $0.01 \mathrm{Nm}$ for $X, Y$ and $Z$ axis torques. The robotic system had a test-retest $\mathrm{SD}$ of $\pm 0.10 \mathrm{~mm}$ and $\pm 0.12^{\circ}$ in translation and rotation between the bone mountings. The tibia was cemented into a 60-mm-diameter stainless steel pot using polymethylmethacrylate (Simplex Rapid, Kemdent, UK). The long axis of the cylinder was perpendicular to the joint surface in the coronal plane and parallel to the long axis of the bone in the sagittal plane. Zero degrees flexion was defined when 3.2-mm guide wires drilled postero-anteriorly through the tibia and femur at 70 and $100 \mathrm{~mm}$ away from the joint line, respectively, were parallel.

\section{Biomechanical testing}

Maintaining $0^{\circ}$ knee flexion, the system minimised the forces and torques in the remaining five DOFs and recorded a known starting point for the intact knee. From this point, the force sensor guided the passive path of knee flexion from $0^{\circ}$ to $90^{\circ}$ while minimising the five remaining forces and torques. Three cycles of flexion-extension 
were performed in order to minimise error from the inherent stress relaxation properties of soft tissue [18]. To quantify knee laxity, the robot held a chosen flexion angle on the passive path and a force/torque was imposed while the remaining 4 DOF were neutralised: $90 \mathrm{~N}$ for antero-posterior (AP) tibial translation, $5 \mathrm{Nm}$ for internal/external rotation (IR/ER) and coupled moments of $4 \mathrm{Nm}$ IR with $8 \mathrm{Nm}$ of valgus to simulate the pivot-shift laxity [22]. The AP, IR, and ER laxities were evaluated at $0^{\circ}, 30^{\circ}, 60^{\circ}$ and $90^{\circ}$ of flexion $[2,11,24,47]$. The simulated pivot shift (SPS) was performed at $0^{\circ}, 15^{\circ}, 30^{\circ}$ and $45^{\circ}$ of flexion $[2,9,11$, $22,24,47]$ and the tibial displacement divided into IR and anterior components.

\section{Surgical technique}

ACL reconstructions were performed by a consultant soft tissue knee surgeon. Each reconstruction was performed first, second, and third on three occasions, eliminating bias. The ACL was resected arthroscopically, leaving 1-mm remnants to guide tunnel placement. A medial parapatellar arthrotomy was performed above the meniscus [14] to accurately visualise the ACL attachments and define the positions of the fibre bundles of the ACL. These were recorded relative to validated arthroscopic landmarks and used to guide subsequent socket placement $[6,20,36]$. The bone tunnels were repaired between reconstructions using a polyester paste by outside-in (femur) or inside-out (tibia) injection [23, 24].

Each reconstruction was performed using a translateral all-inside technique, using outside-in drilling (FlipCutter; Arthrex Inc, Naples, FL) and adjustable length cortical suspensory fixation (ACL TightRope RT, Arthrex) [28, 31, 43]. Grafts were constructed from either a single semitendinosus (SB and 3S) or semitendinosus plus gracilis (DB) tendon, pre-tensioned with $50 \mathrm{~N}$ for $10 \mathrm{~min}$ prior to deployment [2].

Adjustable suspensory fixation devices are closedloop systems, and thus the resultant graft tension cannot be reliably determined from that applied externally during deployment, so a laxity-matching method was used. A Lachman test was performed on the intact knee: $90 \mathrm{~N}$ of anterior tibial force was applied and laxity quantified with a Rolimeter $^{\circledR}$ [37]. Starting at $30 \mathrm{~N}$ [24], the fixations were tensioned by $5 \mathrm{~N}$ increments until the laxity at $20^{\circ}$ [29] was equivocal to the intact knee. The knee was subsequently cycled ten times from $0^{\circ}$ to $120^{\circ}$ and the tensioning procedure repeated. The arthrotomy was not closed, avoiding variability in soft tissue tension.

\section{Anatomic double-bundle reconstruction}

The semitendinosus and gracilis tendons were quadrupled to form individual grafts to replicate the AM and PL bundles, respectively. Each tendon was quadrupled through two ACL fixation devices (TightRope, Arthrex), then transfixed and secured with sutures (0-FiberWire, Arthrex) [31, 46]. The mean diameters of the AM and PL grafts were 8 and $7 \mathrm{~mm}$, respectively. Guide wires were drilled through the centres of the native bundle attachments. Sockets were created to a depth of 25 and $30 \mathrm{~mm}$ on the femur and tibia, respectively. A 2-mm bony bridge was confirmed prior to graft deployment. Outside-in sutures were passed through the tunnels with passage of the PL followed by the AM graft. The cortical buttons were deployed onto the cortex under direct vision to avoid soft tissue impingement. The $\mathrm{PL}$ and $\mathrm{AM}$ bundles were tensioned at $0^{\circ}$ and $60^{\circ}$, respectively [10].

\section{Anatomic single-bundle reconstruction}

A single semitendinosus tendon was quadrupled through two fixation devices and secured as previously described [46], producing a mean graft diameter of $8 \mathrm{~mm}$. The graft tunnels were drilled through the centres of the ACL femoral and tibial attachments and their positions confirmed under direct vision. Graft tensioning was at $30^{\circ}$ knee flexion [45].

\section{Anatomic three-socket reconstruction}

A single semitendinosus tendon was doubled and folded in half, producing a bifurcating graft as previously described [49]. The mean diameter of the single tibial bundle was $8 \mathrm{~mm}$, the femoral AM and PL grafts were each $6 \mathrm{~mm}$. Anatomic socket positions on the femur were identical to the DB technique whilst the anatomic SB mid-bundle position was used on the tibia [20]. The PL and AM bundles were tensioned at $0^{\circ}$ and $60^{\circ}$, respectively [10].

\section{Tunnel position analysis}

After testing, soft tissues were resected and the femur cut in the mid-sagittal plane at the intercondylar notch. True lateral photographs were taken of the medial aspect of the lateral femoral condyle and axial photographs of the tibial plateau (Single-lens reflex, Canon 100D). Overlay grids, as defined by Bernard et al. [5] and Tsuda et al. [44] were placed over the image of each femoral and tibial attachment, respectively, and the centres of the sockets were recorded (ImageJ 1.48, National Institute of Health, Bethesda, Maryland, USA).

\section{Study approval}

The study protocol for obtaining, use and disposal of human tissue specimens received REC Wales approval: 12/ WA/0196, permit number ICHTB HTA licence: 12,275. 


\section{Statistical analysis}

Based on data from a previous study [24], it was determined that for detection of a $2-\mathrm{mm}$ change in anterior translation laxity with $80 \%$ power at the $5 \%$ level of significance, eight knee specimens would be required, based on the SD of the laxity being $\pm 1.4 \mathrm{~mm}$; nine were used, in case of any technical problem during the work. The kinematic data were analysed using a two-factor repeatedmeasures analysis of variance (RM-ANOVA). The two factors assessed were the state of the ACL and the flexion angle of the knee. Five dependent variables (tibial displacements) were evaluated with Bonferroni corrections: anterior translation, internal rotation (IR), external rotation, and anterior translation and IR under coupled loading during the SPS. Pairwise comparisons using a paired $t$ test were performed where appropriate. The level of significance was set at $P<0.05$ for a single comparison. Statistical analysis was performed in SPSS v 21, IBM Corp.

\section{Results}

\section{Anterior tibial translation}

Significant increases in anterior tibial translation laxity were found from the intact to ACL-deficient states at all flexion angles. Similarly, all reconstructions were significantly less lax than the ACL-deficient knee at all flexion angles except $3 \mathrm{~S}$ at $90^{\circ}$. Significant differences were not found between the intact state and any reconstruction, apart from SB being more lax at $60^{\circ}$ of knee flexion. Similarly, significant differences were not found between reconstructions, apart from DB being significantly less lax than SB at $60^{\circ}$ (Table 1; Fig. 2).

\section{Internal/external tibial rotation}

Significant increases in IR and ER were observed from the intact to the ACL-deficient states at all flexion angles tested. Conversely, significant differences in IR and ER were not found between the intact state and any reconstruction, or between reconstructions, at any flexion angle. All reconstructions allowed significantly less IR than the deficient state at $0^{\circ}$, only DB surgery did so at $30^{\circ}$, whilst no reconstruction had significantly less rotation than the deficient knee at $60^{\circ}$ and $90^{\circ}$ (Table 1 ).

\section{Simulated pivot shift}

Significant increases in coupled anterior translation were found from the intact to the ACL-deficient state at all flexion angles tested. Similarly, all reconstructions were significantly less lax than the ACL-deficient knee at all flexion angles apart from SB and $3 \mathrm{~S}$ at $45^{\circ}$. Significant differences in coupled anterior translation were not found between the intact state and any reconstruction at any flexion angle. No significant difference was observed between $\mathrm{SB}$ and $3 \mathrm{~S}$, or $3 \mathrm{~S}$ and $\mathrm{DB}$, at any flexion angle. $\mathrm{DB}$ was significantly less lax than $\mathrm{SB}$ at $15^{\circ}, 30^{\circ}$ and $45^{\circ}$; however, both were similar to the intact knee (Table 1; Fig. 3).

Significant increases in IR under simulated pivot-shift loading were found from the intact to the ACL-deficient state at all flexion angles. All reconstructions were significantly less lax than the ACL-deficient knee at $0^{\circ}$, DB was significantly less lax at $15^{\circ}$ and $30^{\circ}$ and all reconstructions were comparable with the deficient knee at $45^{\circ}$. Significant differences in IR were not found between the intact state and any reconstruction during coupled loading at any flexion angle. No significant difference was observed between SB and $3 \mathrm{~S}$ at any flexion angle. Whilst DB was significantly less lax than $\mathrm{SB}$ at $0^{\circ}, 15^{\circ}$ and $30^{\circ}$, DB and $3 \mathrm{~S}$ laxities were comparable (Fig. 4).

Socket positions after SB, 3S, and DB surgery are listed in Table 2 and shown in Figs. 5 and 6.

\section{Discussion}

The most important finding of this study is that, contrary to the hypothesis, a bifurcating graft with three bone sockets (3S) did not restore native knee laxities significantly more closely to normal than a single-bundle (SB) ACL reconstruction. Laxities after $3 \mathrm{~S}$ and $\mathrm{DB}$ surgery were comparable, with the DB reconstruction providing significantly less laxity than SB surgery under the coupled moments of the simulated pivot shift. Tensioning the ACL grafts to match a quantified Lachman test of the intact knee also offered restoration of intact laxity of IR and the SPS for all reconstructions.

This is the only biomechanical study comparing the kinematics of anatomic single- and multi-bundle ACL reconstructions with total suspensory fixation. This adjustable fixation allowed a laxity-matching graft tensioning protocol to be used, akin to minimising the side-to-side difference clinically; it allowed the knees to be restored close to intact behaviour with all three graft configurations. Previous biomechanical studies have applied a range of pre-determined graft tensions with varied results, often reporting significantly more laxity than the native knee [2, 17, 51], especially during IR and the SPS. This emphasises the value of quantifying the laxity of the 'intact' contralateral knee peroperatively, and subsequent graft tensioning, towards optimising the control of knee rotation at time zero.

Some studies have previously evaluated three-socket grafts of different graft type, configuration or fixation to 
Table 1 Observed translational and rotational differences between knee states

\begin{tabular}{|c|c|c|c|c|c|}
\hline \multirow[t]{2}{*}{ Flexion angle } & \multirow[t]{2}{*}{ Translation at intact state $(\mathrm{mm})$} & \multicolumn{4}{|c|}{ Differences from intact $(\mathrm{mm})$} \\
\hline & & ACL deficient & SB & TriLink & DB \\
\hline \multicolumn{6}{|c|}{ Anterior tibial translation } \\
\hline $0^{\circ}$ & $4.0 \pm 1.4$ & $6.9 \pm 2.2^{\mathrm{i}}$ & $-0.2 \pm 1.2^{\mathrm{d}}$ & $-1.0 \pm 1.0^{\mathrm{d}}$ & $-1.5 \pm 1.4^{\mathrm{d}}$ \\
\hline $30^{\circ}$ & $5.5 \pm 2.0$ & $10.6 \pm 3.4^{\mathrm{i}}$ & $1.7 \pm 1.9^{\mathrm{d}}$ & $1.0 \pm 2.0^{\mathrm{d}}$ & $0.1 \pm 1.5^{\mathrm{d}}$ \\
\hline $60^{\circ}$ & $5.3 \pm 1.7$ & $8.0 \pm 4.1^{\mathrm{i}}$ & $2.0 \pm 1.6^{\mathrm{d}, \mathrm{i}, \mathrm{r}}$ & $1.3 \pm 2.0^{\mathrm{d}}$ & $0.5 \pm 2.0^{\mathrm{d}, \mathrm{r}}$ \\
\hline $90^{\circ}$ & $5.1 \pm 2.2$ & $5.4 \pm 1.6^{\mathrm{i}}$ & $2.0 \pm 2.1^{\mathrm{d}}$ & $1.5 \pm 2.9$ & $0.4 \pm 3.2^{\mathrm{d}}$ \\
\hline \multirow[t]{2}{*}{ Flexion angle } & \multirow[t]{2}{*}{ Translation at intact state (mm) } & \multicolumn{4}{|c|}{ Difference from intact (mm) } \\
\hline & & ACL deficient & SB & TriLink & DB \\
\hline \multicolumn{6}{|c|}{ Simulated pivot shift: anterior tibial translation } \\
\hline $0^{\circ}$ & $2.2 \pm 1.6$ & $3.6 \pm 2.0^{\mathrm{i}}$ & $0.2 \pm 1.3^{\mathrm{d}}$ & $-0.8 \pm 1.5^{\mathrm{d}}$ & $-1.5 \pm 1.2^{\mathrm{d}, \mathrm{i}}$ \\
\hline $15^{\circ}$ & $2.8 \pm 2.2$ & $4.6 \pm 2.0^{\mathrm{i}}$ & $0.8 \pm 1.6^{\mathrm{d}, \mathrm{r}}$ & $-0.0 \pm 1.6^{\mathrm{d}}$ & $-0.8 \pm 0.9^{\mathrm{d}, \mathrm{r}}$ \\
\hline $30^{\circ}$ & $3.4 \pm 2.8$ & $4.5 \pm 2.3^{\mathrm{i}}$ & $1.0 \pm 1.7^{\mathrm{d}, \mathrm{r}}$ & $0.2 \pm 1.8^{\mathrm{d}}$ & $-0.6 \pm 1.2^{\mathrm{d}, \mathrm{r}}$ \\
\hline $45^{\circ}$ & $2.8 \pm 3.0$ & $3.8 \pm 3.3^{\mathrm{i}}$ & $1.1 \pm 1.7^{\mathrm{r}}$ & $0.6 \pm 1.8$ & $0.1 \pm 1.59^{\mathrm{d}, \mathrm{r}}$ \\
\hline \multirow[t]{2}{*}{ Flexion angle } & \multirow[t]{2}{*}{ Rotation at intact state $\left(^{\circ}\right)$} & \multicolumn{4}{|c|}{ Difference from intact $\left(^{\circ}\right)$} \\
\hline & & ACL deficient & SB & TriLink & DB \\
\hline \multicolumn{6}{|c|}{ Simulated pivot shift: internal tibial rotation } \\
\hline $0^{\circ}$ & $10.4 \pm 2.8$ & $3.5 \pm 2.1^{\mathrm{i}}$ & $0.8 \pm 1.1^{\mathrm{d}, \mathrm{r}}$ & $-0.2 \pm 1.5^{\mathrm{d}}$ & $-1.0 \pm 1.2^{\mathrm{d}, \mathrm{r}}$ \\
\hline $15^{\circ}$ & $16.3 \pm 6.1$ & $2.8 \pm 2.1^{\mathrm{i}}$ & $1.6 \pm 1.5^{\mathrm{r}}$ & $0.6 \pm 1.5$ & $-0.2 \pm 1.0^{\mathrm{d}, \mathrm{r}}$ \\
\hline $30^{\circ}$ & $19.0 \pm 8.5$ & $1.6 \pm 1.6^{\mathrm{i}}$ & $1.3 \pm 1.2^{\mathrm{r}}$ & $0.7 \pm 1.0$ & $0.1 \pm 0.6^{\mathrm{r}}$ \\
\hline $45^{\circ}$ & $19.8 \pm 10.0$ & $1.0 \pm 1.0^{\mathrm{i}}$ & $1.0 \pm 1.0$ & $0.5 \pm 0.9$ & $0.5 \pm 0.7$ \\
\hline \multirow[t]{2}{*}{ Flexion angle } & \multirow[t]{2}{*}{ Rotation at intact state $\left(^{\circ}\right)$} & \multicolumn{4}{|c|}{ Difference from intact $\left(^{\circ}\right)$} \\
\hline & & ACL deficient & SB & TriLink & DB \\
\hline \multicolumn{6}{|c|}{ Internal tibial rotation } \\
\hline $0^{\circ}$ & $10.6 \pm 3.1$ & $3.3 \pm 1.7^{\mathrm{i}}$ & $0.5 \pm 1.4^{\mathrm{d}}$ & $-0.9 \pm 1.4^{\mathrm{d}}$ & $-1.4 \pm 1.6^{\mathrm{d}}$ \\
\hline $30^{\circ}$ & $19.2 \pm 9.2$ & $1.8 \pm 1.4^{\mathrm{i}}$ & $0.7 \pm 0.8$ & $0.4 \pm 0.9$ & $-0.1 \pm 0.7^{\mathrm{d}}$ \\
\hline $60^{\circ}$ & $18.6 \pm 9.7$ & $1.1 \pm 0.6^{\mathrm{i}}$ & $0.6 \pm 0.6$ & $0.6 \pm 0.7$ & $0.5 \pm 0.8$ \\
\hline $90^{\circ}$ & $18.4 \pm 10.0$ & $0.8 \pm 0.3^{\mathrm{i}}$ & $0.6 \pm 0.6$ & $0.7 \pm 0.8$ & $0.6 \pm 0.8$ \\
\hline \multirow[t]{2}{*}{ Flexion angle } & Rotation at intact state $\left(^{\circ}\right)$ & \multicolumn{4}{|c|}{ Difference from intact $\left(^{\circ}\right)$} \\
\hline & & ACL deficient & SB & TriLink & DB \\
\hline \multicolumn{6}{|c|}{ External tibial rotation $\left({ }^{\circ}\right)$} \\
\hline $0^{\circ}$ & $12.1 \pm 4.7$ & $0.5 \pm 0.5^{\mathrm{i}}$ & $0.0 \pm 0.9$ & $-0.3 \pm 0.7$ & $-0.1 \pm 0.8$ \\
\hline $30^{\circ}$ & $20.4 \pm 9.2$ & $0.6 \pm 0.4^{\mathrm{i}}$ & $0.1 \pm 0.8$ & $-0.1 \pm 0.6$ & $0.3 \pm 1.1$ \\
\hline $60^{\circ}$ & $21.6 \pm 10.9$ & $0.8 \pm 0.6^{\mathrm{i}}$ & $0.2 \pm 0.9$ & $-0.0 \pm 0.5^{\mathrm{d}}$ & $0.1 \pm 0.7$ \\
\hline $90^{\circ}$ & $21.2 \pm 9.5$ & $0.6 \pm 0.4^{\mathrm{i}}$ & $0.1 \pm 0.9$ & $-0.0 \pm 0.5^{\mathrm{d}}$ & $-0.1 \pm 0.8^{\mathrm{d}}$ \\
\hline
\end{tabular}

Values are expressed as mean \pm standard deviation. Measurements are reported relative to the intact state of each knee. SB, single-bundle reconstruction; $3 \mathrm{~S}$, three-socket reconstruction; DB, double-bundle reconstruction. Statistically significant difference from ${ }^{\mathrm{i}}$ intact state, ${ }^{\mathrm{d}}$ deficient state and ${ }^{\mathrm{r}}$ between reconstructions $(P<0.05)$

that of the present study [23, 35, 47, 48]. Yagi et al. [47] reported that three-tunnel surgery more closely restored intact anterior laxity than an SB reconstruction at $0^{\circ}$ and $30^{\circ}$ and in situ graft forces from $0^{\circ}$ to $60^{\circ}$; both reconstructions failed to restore native anterior restraint from $0^{\circ}$ to $60^{\circ}$ of flexion. Conversely, Yamamoto et al. [48] found no significant difference in anterior laxity between three-tunnel and laterally placed SB except at higher angles of flexion where SB was superior. Petersen et al. [35] compared a similar three-tunnel construct to DB surgery, reporting significantly less anterior laxity at $0^{\circ}$ and $30^{\circ}$ for the latter. In contrast, the present study found no significant difference between $3 \mathrm{~S}$ and DB surgery at any angle of flexion; only the SB at $60^{\circ}$ had significantly 
Fig. 2 Change of anterior tibial translation from native knee laxity, in response to a $90 \mathrm{~N}$ anterior force (Mean $\pm \mathrm{SD}$ ). $\mathrm{SB}$, single-bundle reconstruction; 3S, three-socket reconstruction; DB, double-bundle reconstruction. Significantly less laxity was found between all reconstructions and the deficient state except $3 \mathrm{~S}$ in $90^{\circ}$ of knee flexion
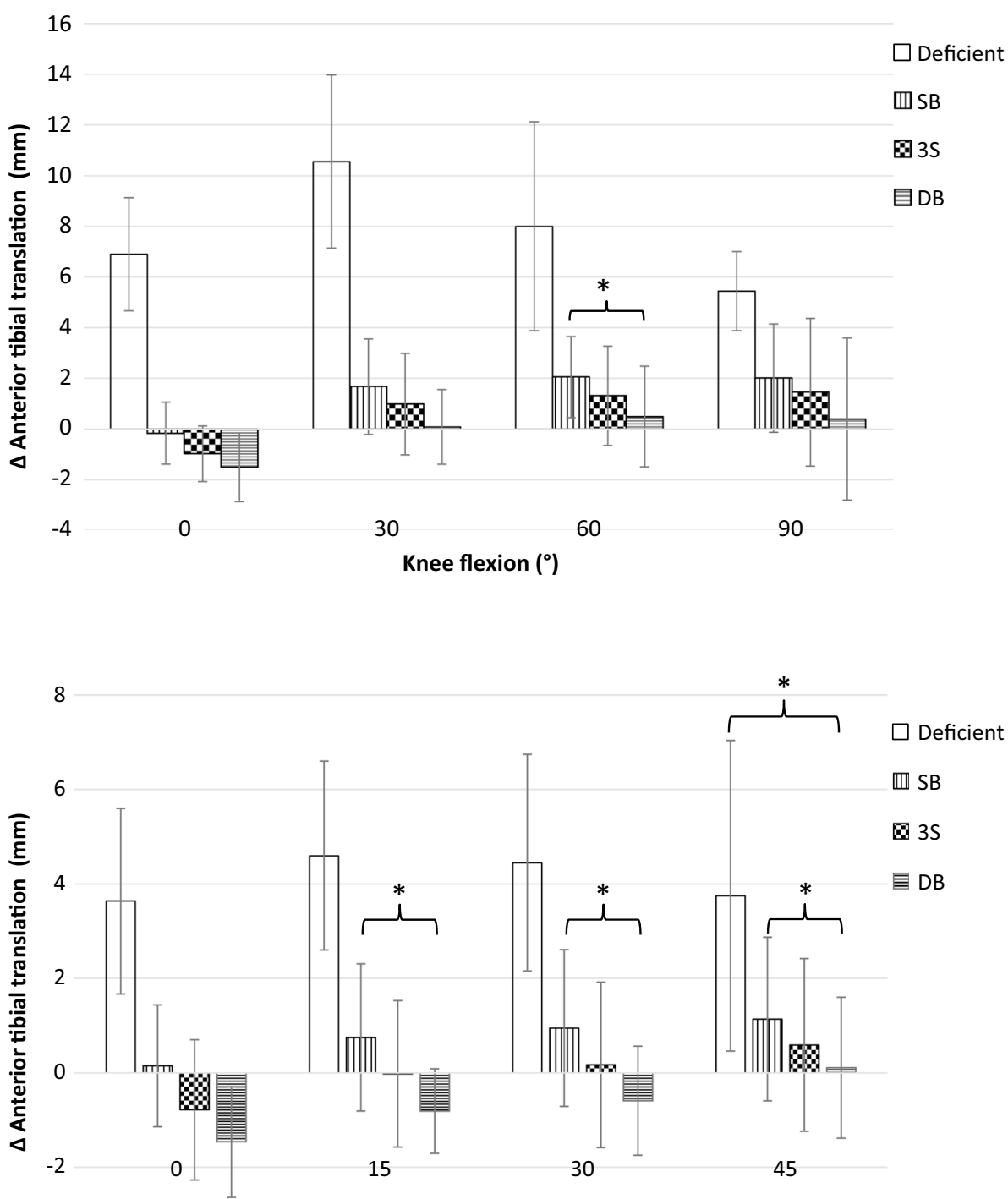

$-4$

Knee flexion $\left({ }^{\circ}\right)$
Fig. 3 Change of coupled anterior tibial translation from native knee laxity in response to combined $4 \mathrm{~N}$-m of internal tibial and $8 \mathrm{~N}-\mathrm{m}$ of valgus torques (Mean $\pm \mathrm{SD}$ ). SB, single-bundle reconstruction; 3S, three-socket reconstruction; $\mathrm{DB}$, double-bundle reconstruction. Significantly less laxity was found between all reconstructions and the deficient state except for $\mathrm{SB}$ and $3 \mathrm{~S}$ in $45^{\circ}$ of knee flexion greater laxity. Kim et al. [23] compared the kinematics of four anatomic quadriceps ACL grafts: three-bundle SB with two femoral and one tibial sockets, three-bundle SB with two tibial and one femoral sockets, and DB reconstruction. All multi-bundle reconstructions were similar to the intact with significantly less anterior laxity than SB at $60^{\circ}$ and $90^{\circ}$, whilst no difference was seen between the SB and deficient states at these flexion angles. In the present study, the SB was tensioned at $30^{\circ}$ rather than in extension; this may have contributed to an improved performance at greater angles of knee flexion.

A number of studies have reported coupled tibial displacements in response to SPS loading. Kim et al. [23] found no differences in ATT between any knee state under simulated pivot shift, but found significantly lower forces in the $\mathrm{SB}$ construct than the intact $\mathrm{ACL}$ from $0^{\circ}$ to $30^{\circ}$ and significantly higher forces in DB and one-femur/two-tibia tunnel constructs at $15^{\circ}$ and $30^{\circ}$, respectively. In contrast, this study found significant increases of coupled motion between the intact and ACL-deficient states at extension and early flexion, similar to previous work [14, 48]. Yagi et al. [47] found significantly less coupled ATT during the SPS after two-femur/two-tibia reconstruction than SB surgery, but it remained significantly more than the intact state. Petersen et al. [35] reported a similar superiority of DB over a two-femur/one-tibia graft, with significantly less ATT at $0^{\circ}$ and $30^{\circ}$ whilst also remaining significantly more lax than the intact state. Similarly to Yamamoto et al. [48], this study found that anatomic SB and a two-femur/onetibia graft (3S) were able to restore ATT to values similar 
Fig. 4 Change of internal tibial rotation from the laxity of the native knee in response to combined $4 \mathrm{~N}-\mathrm{m}$ of internal tibial and $8 \mathrm{~N}-\mathrm{m}$ of valgus torques (Mean $\pm \mathrm{SD}$ ). SB, singlebundle reconstruction; $3 \mathrm{~S}$, three-socket reconstruction; DB, double-bundle reconstruction

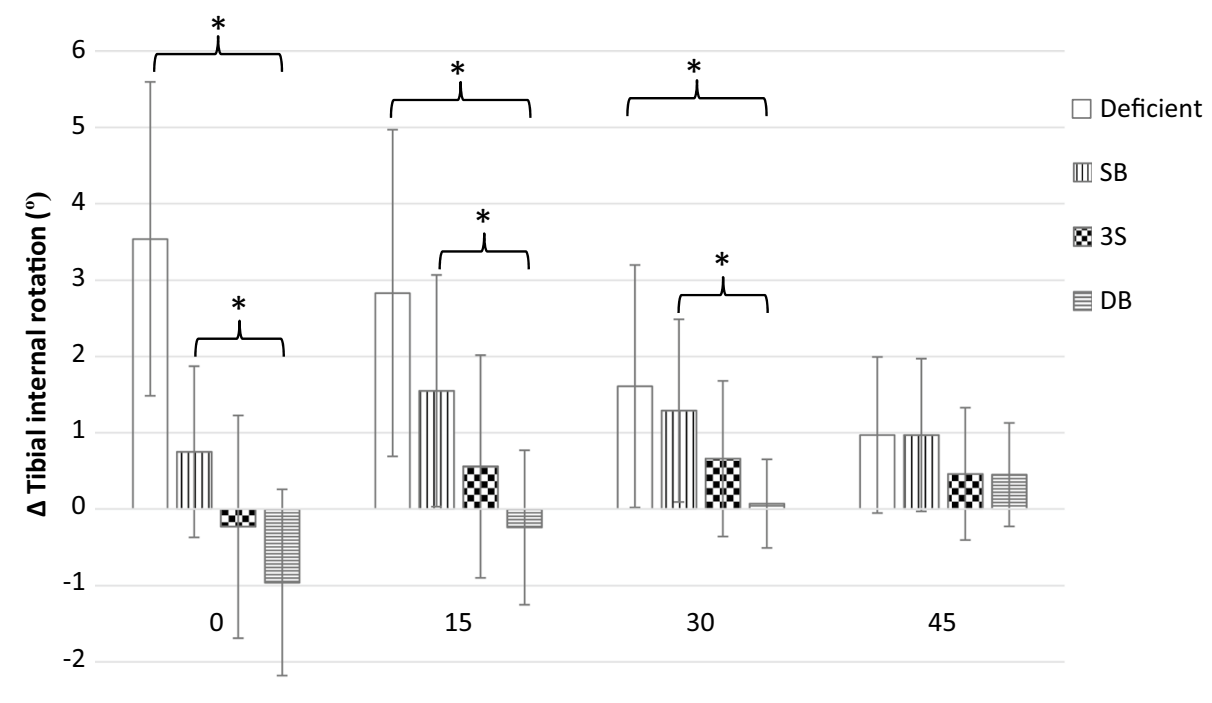

Knee flexion $\left({ }^{\circ}\right)$
Table 2 Mean socket positions following post hoc analysis

\begin{tabular}{lllll}
\hline & & AM (\%) & MB (\%) & PL (\%) \\
\hline \multirow{2}{*}{ Femur } & Proximal-distal & $21 \pm 2$ & $29 \pm 2$ & $34 \pm 2$ \\
& Anterior-posterior & $23 \pm 3$ & $35 \pm 2$ & $47 \pm 4$ \\
Tibia & Medial-lateral & $47 \pm 1$ & $48 \pm 1$ & $49 \pm 1$ \\
& Anterior-posterior & $32 \pm 3$ & $44 \pm 2$ & $51 \pm 3$ \\
\hline
\end{tabular}

On the femur, measurements start from $0 \%$ at the proximal, anterior edge of a superimposed grid aligned with the roof of the femoral notch - the zero position was deep and high in the notch (Fig. 5). On the tibia, measurements started at $0 \%$ from the anteromedial corner of the grid fitted to the tibial plateau (Fig. 6)

$A M$ anteromedial bundle, $M B$ mid-bundle, $P L$ posterolateral bundle

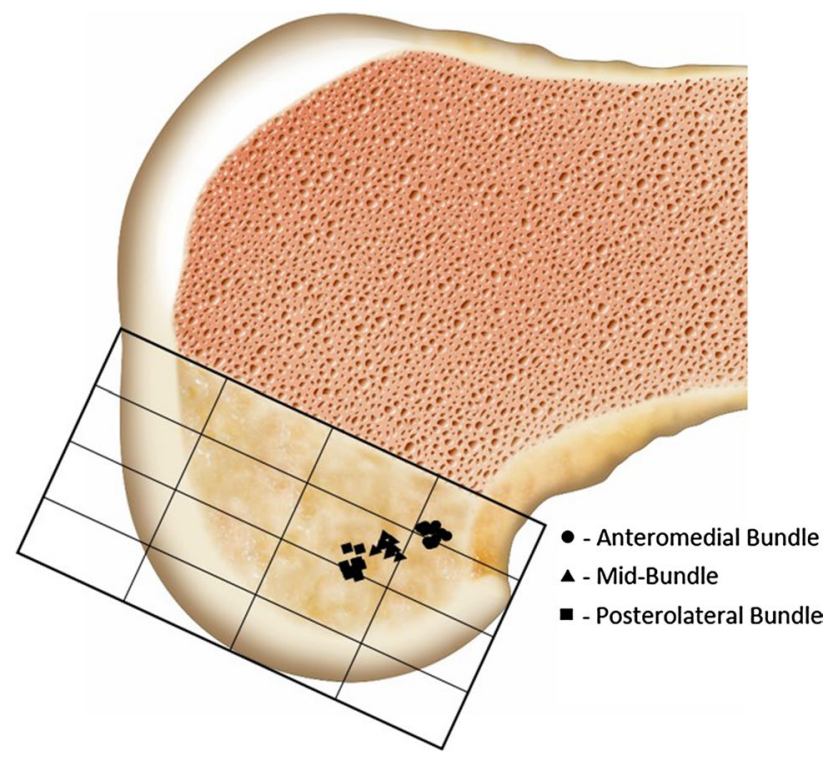

Fig. 5 Post hoc analysis of the three socket positions on the femur to the intact state. DB surgery had a tendency to over-constrain the joint in extension, which has been reported previously [25].

The present study further examined the IR component of the simulated pivot shift, and all reconstructions were comparable to the intact state. In contrast to Kondo et al. [25], significant increases in IR were seen between the intact and ACL-deficient states at all flexion angles. This remained true for SB and 3S, whilst DB surgery maintained significantly less laxity than the deficient state at $0^{\circ}$ and $15^{\circ}$, as well as the SB state from $0^{\circ}$ to $30^{\circ}$, near the angle at which the pivot shift occurs [12]. These findings were consistent with previous work suggesting that SB and two-femur/ one-tibia $3 \mathrm{~S}$ grafts produced sufficient control at $15^{\circ}$, but became less efficacious with increased knee flexion [48].

There are several limitations of the present study. Firstly, the specimens were $66 \pm 8$ years old, higher than the patient group who experience ACL rupture, but comparable to similar cadaveric studies [24, 43]. The clinical pivot shift is a dynamic examination through a range of motion. We were unable to replicate this using a single robotic manipulator, and the combined moments were imposed at a static flexion angle, therefore this and other studies [14, 23, 47] have not mimicked the in vivo kinematics but only the coupled laxities. These results represent time-zero data and do not account for ACL graft and other soft tissue changes during rehabilitation. This may be particularly relevant in the context of the initially over-constrained knee that may settle to a clinically effective reconstruction. Finally, there was no muscle loading, so these results reflect passive restraints, as in clinical laxity testing. The advantages of the study design, however, included the ability to perform three ACL reconstructions in each knee, thus allowing the 
Fig. 6 Post hoc analysis of the three socket positions on the tibia

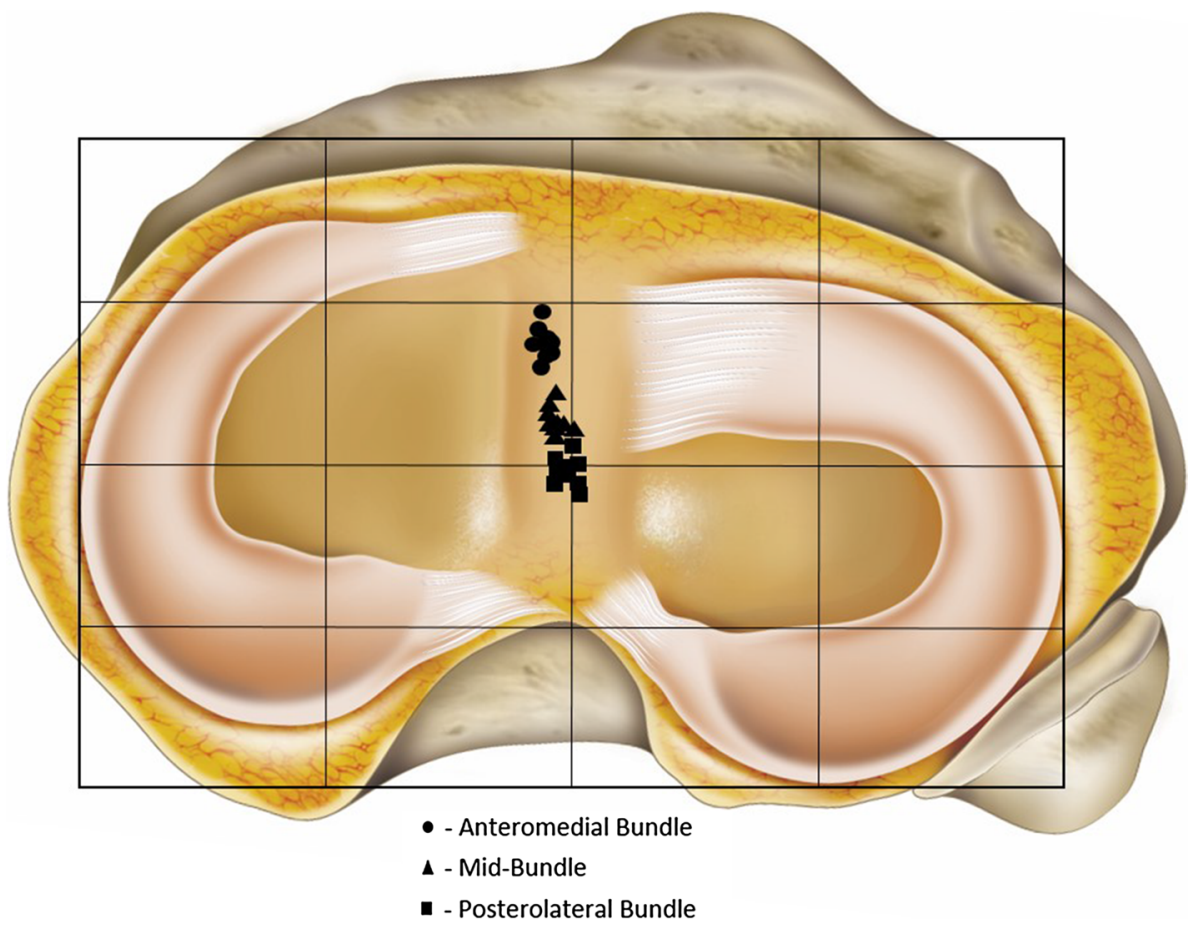

within-specimen repeated-measures statistical analysis to discern their relative performances without inter-specimen variability.

The clinical relevance of this work relates to the choice of ACL reconstruction, and how that choice is affected by differences in the resulting laxity of the knee, among the $\mathrm{SB}, 3 \mathrm{~S}$, and DB constructs in this study. This study suggests equivalence for $\mathrm{SB}, 3 \mathrm{~S}$, and $\mathrm{DB} \mathrm{ACL}$ reconstructions in their control of tibial anterior translation and rotation. This supports the use of a correctly positioned SB graft; while there was a consistent trend for reduced laxity with $3 \mathrm{~S}$ over SB, it was not significant during any single comparison. Yasuda et al. [50] reported significantly better control of ATT and the pivot shift 2 years after DB compared to SB surgery. In keeping with the present study, the two-femur/one-tibia graft produced comparable laxity to the DB but not significantly less than the SB, despite a reported increase in stability with complete attachment site restoration [40]. The three-socket $3 \mathrm{~S}$ surgery is less complicated than DB surgery yet produced comparable results; it preserves bone stock and spares gracilis, which is beneficial in the context of multi-ligament injury. This study suggests that it could be considered as an alternative to DB surgery. The literature reports a wide variety of graft tensions during ACL reconstruction [2, 17, 51], and although tensioning devices are available, no definitive clinical benefit has been reported [38]. This study suggests that quantifying the Lachman test of the uninjured knee and using this as a tensioning guide closely restores native knee laxity.

\section{Conclusion}

Although three-socket reconstruction restored laxities to a similar extent to DB, no superiority over SB surgery was observed. Statistically significant differences were found between SB and DB surgery during anterior tibial and SPS loading during early flexion; however, both remained similar to that observed in the native knee. Single-bundle surgery, with anatomic tunnel position and the laxity matched to the native knee by use of adjustable fixation, provided clinically equivalent control of rotation compared with the intact knee.

\section{Compliance with ethical standards}

Conflict of interest A. Wilson was a consultant to Arthrex Co. at the time of this study.

Funding This study was funded by the Basingstoke and North Hampshire Hospital Orthopaedic Research Fund. Surgical consumables and arthroscopy equipment were donated and lent by the Arthrex Co. The robotic test system and Dr El Daou were supported by The Centre of Excellence for the Application of Technology in the Treatment of Osteoarthritis at Imperial College London, supported by the Wellcome Trust and the EPSRC.

Ethical approval The study protocol for obtaining, use and disposal of human tissue specimens received REC Wales approval: 12/ WA/0196, permit number ICHTB HTA licence: 12275.

Informed consent Not applicable to this study. 
Open Access This article is distributed under the terms of the Creative Commons Attribution 4.0 International License (http://creativecommons.org/licenses/by/4.0/), which permits unrestricted use, distribution, and reproduction in any medium, provided you give appropriate credit to the original author(s) and the source, provide a link to the Creative Commons license, and indicate if changes were made.

\section{References}

1. Amis A, Zavras TD (1995) Isometricity and graft placement during anterior cruciate ligament reconstruction. Knee 2:5-17

2. Anderson CJ (2010) Kinematic impact of anteromedial and posterolateral bundle graft fixation angles on double-bundle anterior cruciate ligament reconstructions. Am J Sports Med 38:1575-1583

3. Bedi A, Altchek DW (2009) The "footprint" anterior cruciate ligament technique: an anatomic approach to anterior cruciate ligament reconstruction. Arthroscopy 25:1128-1138

4. Bedi A, Musahl V, O'Loughlin P, Maak T, Citak M, Dixon P, Pearle AD (2010) A comparison of the effect of central anatomical single-bundle anterior cruciate ligament reconstruction and double-bundle anterior cruciate ligament reconstruction on pivot-shift kinematics. Am J Sports Med 38:1788-1794

5. Bernard M, Hertel P, Hornung H, Cierpinski T (1997) Femoral insertion of the ACL: radiographic quadrant method. Am J Knee Surg 10:14-21

6. Bird JH, Carmont MR, Dhillon M, Smith N, Brown C, Thompson P, Spalding T (2011) Validation of a new technique to determine midbundle femoral tunnel position in anterior cruciate ligament reconstruction using 3-dimensional computed tomography analysis. Arthroscopy 27:1259-1267

7. Brophy RH, Wright RW, Matava MJ (2009) Cost analysis of converting from single-bundle to double-bundle anterior cruciate ligament reconstruction. Am J Sports Med 37:683-687

8. Crawford C, Nyland J, Landes S, Jackson R, Chang HC, Nawab A, Caborn DN (2007) Anatomic double bundle ACL reconstruction: a literature review. Knee Surg Sports Traumatol Arthrosc 15:946-964

9. Engebretsen L, Wijdicks CA, Anderson CA, Westerhaus B, LaPrade RF (2012) Evaluation of a simulated pivot shift test: a biomechanical study. Knee Surg Sports Traumatol Arthrosc 20:698-702

10. Fu FH, Shen W, Starman JS, Okeke N, Irrgang JJ (2008) Primary anatomic double-bundle anterior cruciate ligament reconstruction a preliminary 2-year prospective study. Am J Sports Med 36:1263-1274

11. Gabriel MT, Wong EK, Woo SL, Yagi M, Debski RE (2004) Distribution of in situ forces in the anterior cruciate ligament in response to rotatory loads. J Orthop Res 22:85-89

12. Galway R, Beaupre A, MacIntosh D (1972) Pivot shift: a clinical sign of symptomatic anterior cruciate insufficiency. J Bone Joint Surg Br 54:763-764

13. Girgis FG, Marshall JL, Al-Monajem A (1975) The cruciate ligaments of the knee joint: anatomical. functional and experimental analysis. Clin Orthops Rel Res 106:216-231

14. Goldsmith MT, Jansson KS, Smith SD, Engebretsen L, LaPrade RF, Wijdicks CA (2013) Biomechanical comparison of anatomic single-and double-bundle anterior cruciate ligament reconstructions an in vitro study. Am J Sports Med 41:1585-1604

15. Hara K, Mochizuki T, Sekiya I, Yamaguchi K, Akita K, Muneta $\mathrm{T}$ (2009) Anatomy of normal human anterior cruciate ligament attachments evaluated by divided small bundles. Am J Sports Med 37:2386-2391
16. Hefzy M, Grood ES (1986) Sensitivity of insertion locations on length patterns of anterior cruciate ligament fibers. J Biomech Eng 108(73-82): 17

17. Höher J, Kanamori A, Zeminski J, Fu FH, Woo SL (2001) The position of the tibia during graft fixation affects knee kinematics and graft forces for anterior cruciate ligament reconstruction. Am J Sports Med 29:771-776

18. Howard ME, Cawley PW, Losse GM, Johnston RB (1996) Bone-patellar tendon-bone grafts for anterior cruciate ligament reconstruction: the effects of graft pretensioning. Arthroscopy 12:287-292

19. Hussein M, van Eck CF, Cretnik A, Dinevski D, Fu FH (2012) Prospective randomized clinical evaluation of conventional single-bundle, anatomic single-bundle, and anatomic double-bundle anterior cruciate ligament reconstruction: 281 cases with 3- to 5-year follow-up. Am J Sports Med 40:512-520

20. Hwang MD, Piefer JW, Lubowitz JH (2012) Anterior cruciate ligament tibial footprint anatomy: systematic review of the $21 \mathrm{st}$ century literature. Arthroscopy 28:728-734

21. Järvelä T, Moisala AS, Sihvonen R, Järvelä S, Kannus P, Järvinen M (2008) Double-bundle anterior cruciate ligament reconstruction using hamstring autografts and bioabsorbable interference screw fixation prospective, randomized, clinical study with 2-year results. Am J Sports Med 36:290-297

22. Kanamori A, Zeminski J, Rudy TW, Li G, Fu FH, Woo SL (2002) The effect of axial tibial torque on the function of the anterior cruciate ligament: a biomechanical study of a simulated pivot shift test. Arthroscopy 18:394-398

23. Kim D, Asai S, Moon CW, Hwang SC, Lee S, Keklikci K, LindeRosen M, Smolinski P, Fu FH (2015) Biomechanical evaluation of anatomic single-and double-bundle anterior cruciate ligament reconstruction techniques using the quadriceps tendon. Knee Surg Sports Traumatol Arthrosc 23:687-695

24. Kondo E, Merican AM, Yasuda K, Amis AA (2011) Biomechanical comparison of anatomic double-bundle, anatomic single-bundle, and nonanatomic single-bundle anterior cruciate ligament reconstructions. Am J Sports Med 39:279-288

25. Kondo E, Merican AM, Yasuda K, Amis AA (2010) Biomechanical comparisons of knee stability after anterior cruciate ligament reconstruction between 2 clinically available transtibial procedures: anatomic double bundle versus single bundle. Am J Sports Med 38:1349-1358

26. Kondo E, Yasuda K, Azuma H, Tanabe Y, Yagi T (2008) Prospective clinical comparisons of anatomic double-bundle versus single-bundle anterior cruciate ligament reconstruction procedures in 328 consecutive patients. Am J Sports Med 36:1675-1687

27. Lee JS, Kim TH, Kang SY, Lee SH, Jung YB, Koo S, Chang SH, Lee WB, Jung HJ (2012) How isometric are the anatomic femoral tunnel and the anterior tibial tunnel for anterior cruciate ligament reconstruction? Arthroscopy 28:1504-1512

28. Logan JS, Elliot RR, Wilson AJ (2012) TransLateral ACL reconstruction: a technique for anatomic anterior cruciate ligament reconstruction. Knee Surg Sports Traumatol Arthrosc 20:1289-1292

29. Logan MC, Williams A, Lavelle J, Gedroyc W, Freeman M (2004) What really happens during the Lachman test? a dynamic MRI analysis of tibiofemoral motion. Am J Sports Med 32:369-375

30. Lorbach O, Kieb M, Domnick C, Herbort M, Weyers I, Raschke M, Engelhardt M (2015) Biomechanical evaluation of knee kinematics after anatomic single-and anatomic double-bundle ACL reconstructions with medial meniscal repair. Knee Surg Sports Traumatol Arthrosc 23:2734-2741

31. Lubowitz JH, Ahmad CS, Anderson K (2011) All-inside anterior cruciate ligament graft-link technique: second-generation, noincision anterior cruciate ligament reconstruction. Arthroscopy $27: 717-727$ 
32. Markolf KL, Park S, Jackson SR, McAllister DR (2009) Anterior-posterior and rotatory stability of single and double-bundle anterior cruciate ligament reconstructions. J Bone Joint Surg Am 91:107-118

33. Morimoto Y, Ferretti M, Ekdahl M, Smolinski P, Fu FH (2009) Tibiofemoral joint contact area and pressure after single- and double-bundle anterior cruciate ligament reconstruction. Arthroscopy 25:62-69

34. Musahl V, Voos JE, O’Loughlin PF, Choi D, Stueber V, Kendoff D, Pearle AD (2010) Comparing stability of different single- and double-bundle anterior cruciate ligament reconstruction techniques: a cadaveric study using navigation. Arthroscopy 26(Suppl):S41-S48

35. Petersen W, Tretow H, Weimann A, Herbort M, Fu FH, Raschke M, Zantop T (2007) Biomechanical evaluation of two techniques for double-bundle anterior cruciate ligament reconstruction one tibial tunnel versus two tibial tunnels. Am J Sports Med 35:228-234

36. Piefer JW, Pflugner TR, Hwang MD, Lubowitz JH (2012) Anterior cruciate ligament femoral footprint anatomy: systematic review of the 21st century literature. Arthroscopy 28:872-881

37. Schuster AJ, McNicholas MJ, Wachtl SW, McGurty DW, Jakob RP (2004) A new mechanical testing device for measuring anteroposterior knee laxity. Am J Sports Med 32:1731-1735

38. Sherman SL, Chalmers PN, Yanke AB, Bush-Joseph CA, Verma NN, Cole BJ, Bach BR (2012) Graft tensioning during knee ligament reconstruction: principles and practice. J Am Acad Orthop Surg 20:633-645

39. Sidles JA, Larson RV, Garbini JL, Downey DJ, Matsen FA (1988) Ligament length relationships in the moving knee. J Orthop Res 6:593-610

40. Siebold R (2011) The concept of complete footprint restoration with guidelines for single- and double-bundle ACL reconstruction. Knee Surg Sports Traumatol Arthrosc 19:699-706

41. Smith JO, Yasen S, Risebury MJ, Wilson AJ (2014) Femoral and tibial tunnel positioning on graft isometry in anterior cruciate ligament reconstruction: a cadaveric study. J Orthop Surg 22:318-324

42. Suomalainen $P$, Järvelä T, Paakkala A, Kannus P, Järvinen $M$ (2012) Double-bundle versus single-bundle anterior cruciate ligament reconstruction: a prospective randomized study with 5-year results. Am J Sports Med 40:1511-1518

43. Tsai AG, Wijdicks CA, Walsh MP, Laprade RF (2010) Comparative kinematic evaluation of all-inside single-bundle and doublebundle anterior cruciate ligament reconstruction: a biomechanical study. Am J Sports Med 38:263-272
44. Tsuda E, Ishibashi Y, Fukuda A, Yamamoto Y, Tsukada H, Ono $S$ (2010) Tunnel position and relationship to postoperative knee laxity after double-bundle anterior cruciate ligament reconstruction with a transtibial technique. Am J Sports Med 38:698-706

45. van Eck CF, Samuelsson K, Vyas SM, van Dijk CN, Karlsson J, Fu FH (2011) Systematic review on cadaveric studies of anatomic anterior cruciate ligament reconstruction. Knee Surg Sports Traumatol Arthroscopy 19:S101-S108

46. Wilson AJ, Yasen SK, Nancoo T, Stannard R, Smith JO, Logan JS (2013) Anatomic all-inside anterior cruciate ligament reconstruction using the translateral technique. Arthrosc Tech 2:e99-e104

47. Yagi M, Wong EK, Kanamori A, Debski RE, Fu FH, Woo SL (2002) Biomechanical analysis of an anatomic anterior cruciate ligament reconstruction. Am J Sports Med 30:660-666

48. Yamamoto Y, Hsu WH, Woo SL, van Scyoc AH, Takakura Y, Debski RE (2004) Knee stability and graft function after anterior cruciate ligament reconstruction a comparison of a lateral and an anatomical femoral tunnel placement. Am J Sports Med 32:1825-1832

49. Yasen SK, Logan JS, Smith JO, Nancoo T, Risebury MJ, Wilson AJ (2014) TriLink: anatomic double-bundle anterior cruciate ligament reconstruction. Arthrosc Tech 3:e13-e20

50. Yasuda K, Kondo E, Ichiyama H, Tanabe Y, Tohyama H (2006) Clinical evaluation of anatomic double-bundle anterior cruciate ligament reconstruction procedure using hamstring tendon grafts: comparisons among 3 different procedures. Arthroscopy 22:240-251

51. Yasuda K, Tsujino J, Tanabe Y, Kaneda K (1997) Effects of initial graft tension on clinical outcome after anterior cruciate ligament reconstruction autogenous doubled hamstring tendons connected in series with polyester tapes. Am J Sports Med 25:99-106

52. Zaffagnini S, Bruni D, Marcheggiani Muccioli GM, Bonanzinga T, Lopomo N, Bignozzi S, Marcacci M (2011) Single-bundle patellar tendon versus non-anatomical double-bundle hamstrings ACL reconstruction: a prospective randomized study at 8-year minimum follow-up. Knee Surg Sports Traumatol Arthrosc 19:390-397 